\title{
Medical Physicists Opt for Decentralisation
}

\begin{abstract}
Pieter Inia from the Department of Clinical Physics, Katholike Universiteit Leuven, summarises the role of medical physicists and the steps being taken to ensure that their professional qualifications meet the highest possible standards.
\end{abstract}

Scientific thought became an important factor in medicine in the 17th century, and by the early 2 oth century it was clear that, generally speaking, no single person could have sufficient knowledge of biomedicine and physics to make important and fundamental contributions in both fields. So together with other scientists, physicists became involved in medical work. After Röntgen's discovery of X-rays, applications of ionizing radiation developed into an important field of interest: Marie Curie isolated radium and then set up mobile $\mathrm{x}$-ray imaging units in field hospitals behind the front lines during the 1st World War; artificial radionuclides were introduced into medical practice soon after the 2nd World War.

The number of medical physicists in clinical practice began to rise steeply in the 1960 s following the introduction of cobalt-6o radiation therapy, linear accelerators and gammaray cameras. In the same way as a pharmacist is responsible for the delivery of drugs, a medical physicist working in radiotherapy is responsible for the delivery, from a therapy unit, of a prescribed quantity of ionizing radiation to a prescribed volume in the patient.

The number of areas of medical practice which interest physicists has increased considerably in recent years with the introduction of lasers, microelectronics, sensor technology, computerized imaging techniques, etc. For example, medical physicists now play an important role in developing anatomical and functional imaging based on magnetic resonance of the body's constituents.

\section{Medical Physicists Today}

Two categories of medical physicist can be identified based on their principal objectives, although many medical physicists span both categories. The first consists of medical physicists working as teachers and scientists in universities and medical schools, or as scientists in industry. The nature of their employment essentially defines their (mainly scientific) role and responsibilities.

The other category covers the medical physics carried out in clinical practice in institutions and hospitals; it is well developed and generally recognized as an essential part of medical care and health services. Two functions can be distinguished in clinical medical physics. One is professional, being fulfilled through a special competence in a particular field of clinical medical physics, which is not found among any other medical, paramedical or technical specialty. A specialist working in clinical medical physics is responsible for training all of those involved, both medical and non-medical. As a member of a team of professionals responsible for the diagnosis and treatment of patients, the medical physicist has a direct influence on diagnosis, therapy and safety procedures used in health care. The professional roles and responsibilities of physicists as part of the medical team should be clear and well defined.

The second function is managerial: the medical physicist helps administer a hospital's medical physics, reporting to the institution's highest administrative level. Owing to the relatively large amount of high-cost equipment involved, the medical physicist's expertise and knowledge with regard to supervision and management is generally highly appreciated.

\section{EFOMP Established}

Most European countries have national organisations for what is comprehensively termed medical physics. However, the practice of medical physics varies from country-tocountry, with differing educational requirements and legal status. Representatives of national organisations for medical physics felt a pressing need to harmonize these differences in order to achieve the objectives of freedom of movement and employment within the European Union (EU) Member States. In 1980, when these representatives came together to inaugurate the European Federation of Organisations for Medical Physics (EFOMP), they decided, however, not to limit membership to the then European Community countries, but to embrace all of Europe.

Recognizing that medical physics covers today the very broad field of physics applied directly or indirectly in health care, representatives of the various national organisations for medical physics used the following definition as a preamble to EFOMP's Constitution:

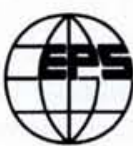

\section{European Physical Society EurophysNet - http:/epswww.epfl.ch/} Published by Europhysics News to inform members. Editor: P.G. Boswell, EPS, BP 69, CH1213, Petit-Lancy 2 - peter.boswell@cern.ch Tel +41-22-7931130 - Fax+41-22-79313

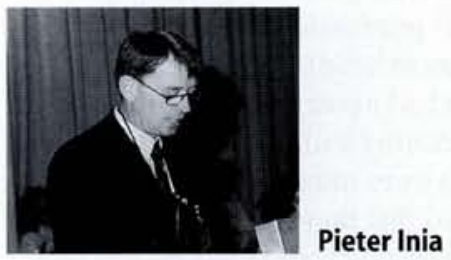

In most European countries there are national organisations: - in which the principal defined category are persons, qualified with a university degree or equivalent in physics, mathematics, computing sciences, physical chemistry, mechanical or electrical or electronic engineering, and working in alliance with medical staff in hospitals, universities or research institutes; - and which carry the responsibility of guiding and supporting the professional character of the work of their members and encouraging and promulgating the scientific work of their members. Their activities and field of work are described by the comprehensive expression: Medical Physics.

A major initiative has been to harmonize the various education schemes for medical physicists in Europe, and to assure a certain level of competence. Practical experience in a medical environment is considered paramount for a well-trained medical physicist.

Another, closely related initiative concerns professional qualifications. While some national organisations of medical physicists have established registration schemes, EFOMP has taken the lead by creating a mechanism for the proper recognition of medical physics by means of approved National Registration Schemes. As an EFOMP Policy Statement [1] puts it: EFOMP does not have the resources to set up and run a centralised registration scheme. Nor would this accommodate the rather varied local circumstances in the different countries. Therefore member organisations are encouraged to set up their own Registration Schemes. They can be either Statutory or Indicative (i.e., voluntary), but must satisfy general criteria laid down by EFOMP if they are to be recognized by EFOMP.

From its inception EFOMP has sought to establish a close working relationship with the European Commission (EC), mainly by 
responding to Directives which impinge on the practice of medical physics, such as those relating to education and training [2]. EFOMP is now accepted by the EC as the body which speaks for medical physics in Europe.

EFOMP should also be seen as the competent body to decide how the European Physicist (Eur Phys) qualification set up recently by the European Physical Society will be applied in the context of medical physics. EFOMP is the obvious partner in setting the standards for Eur Phys accorded to applicants whose main area of training and experience involves medical physics. The necessary coordination is achieved by having a member of the EFOMP executive committee on the Register Commission that awards Eur Phys.

\section{References}

[1] Recommended guidelines on National Registration Schemes for Medical Physicists, Policy Statement No. 6, Physica Medica 11 (1995) 157. [2] Council Directive of 21 December 1988 on the general system for the recognition of higher education diplomas, etc., Off. J. of the European Communities 32 (1989) 16.

\section{EFOMP}

The European Federation of Medical Physicists aims to: - foster and co-ordinate the activities of its member organisations in the field of medical physics, and to collaborate where appropriate with national and international organisations, particularly the International Organisation for Medical Physics (IOMP); - encourage exchanges between member organisations and the dissemination of professional and scientific information through publications and meetings; - encourage scholarships and the exchange of medical physicists between countries;

- propose guidelines for education, training and accreditation programmes;

- make recommendations on the appropriate general responsibilities, organisational relationships and roles of workers in the field of medical physics;

- encourage the formation of organisations for medical physics where such organisations do not exist.

Membership of EFOMP is open to the organisation in each European country responsible for the professional and scientific work of medical physicists (it is not open to individuals). EFOMP has seen a steady increase in membership, and now represents 26 national societies in which 5500 individual medical physicists are organised all over Europe. One of the Federation's roles

\section{Education Network to be Funded}

Hendrik Ferdinande (Ghent University), the Coordinator of the European Physics Education Network (EUPEN), reports that the network has been accepted as a Thematic Network in the European Union's SOCRATES Programme. Subject to approval by the Union's financial committee, EUPEN will receive 70000 ECU for the first year of operation. Some 80 networks were chosen from among over 500 expressions of interest, of which about 30 were retained.

EUPEN [EN 26 (1995) 69] grew out of the Thematic Evaluation Conference on Physics which EPS helped organize. A Steering Committee will manage EUPEN, and act as the reference point for EUPEN activities. It was spun off from from the conference's Scientific Committee and it will call for advice from the Scientific Committee when necessary. The EPS Interdivisional Group for Physics Education will be coordinating activities with EUPEN.

The two committees aim to establish a consortium agreement or founding convention for the institutions that take part in EUPEN. The actual EUPEN structure will be optimised once the level of involvement of each partner institution is known.

EUPEN's general aims will be achieved through the combined action of five working groups that will treat physics education in a comparative manner. Contact persons from partner institutions to serve and take the lead in one (or more) of the groups are presently being sought. The groups, whose activities will mainly involve conferences and questionnairebased peer review, cover:

- the student experience: measurement of workloads, assessment of teaching quality, implementation of the European Credit Transfer Scheme, etc.
- curricula structure and development: 1st, 2nd and 3 rd levels/cycles, course content and specialisation, physics and/or engineering physics, communication skills, etc.

- organisation of physics studies: comparative statistics, number of students at the various levels, cost per student, numerus clausus, fees, student grants, financial support, etc.

- career aspects: recruitment, job orientation, industrial needs, research opportunities, postdoctoral positions, etc.

- research in physics teaching at the University level (distance learning, computer-assisted laboratories, etc.) and at the school level (teacher training, permanent learning, etc.).

A preliminary list of the 107 partner institutions, with details of contact persons, is available at the EUPEN WWW site (http://allserv.rug.ac.be/ hferdin/eupen/list.html) via EurophysNet (http://epswww.epfl.ch). Contact hendrik.ferdinande@rug.ac.be (fax: + 32-9-264 6699 for further information. is to stimulate the organisation of medical physicists in east and central Europe.

The activities of EFOMP are controlled by an annual meeting of Council, in which all member organisations are represented, while the activities are initiated and coordinated by an executive committee.

EFOMP has been able to raise, at an internationa level in Europe, the awareness of medical physics and the position of medical physicists, particularly through the presentation of policy documents. Council has adopted and published policy documents on: the roles, responsibilities and status of the clinical medical physicist; the education and training of medical physics; departments of medical physics; guidelines for national registration schemes.

Since its foundation the Federation has maintained contact with the individual members of national organisations by publishing the bulletin European Medical Physics News, giving news items and details of activities. EFOMP sponsors three international journals and to create opportunities for personal contacts and scientific exchanges, it has initiated a series of triennial conferences on medical physics in close cooperation with the various national organisations.

Information: EFOMP General Office, 4 Campleshon Rd., York Y02 1PE, UK

Tel.: +44-1904-61 0821 - Fax: +44-1904-61 2279

\section{Council Delegate}

L.J.F. Hermans from the Huygens Laboratory, Leiden, has been elected as a Delegate to the EPS Council of the Individual Ordinary Members following a postal ballot.

\section{Interdivisional WWW Sites}

Interdivisional Groups have announced that information on their activities is available on the World-Wide Web as follows:

- Experimental Physics Control Systems: http://hpcoopo1.cern.ch/EPCS

- Accelerators:

http://www.cern.ch/epac/welcome.html

\section{Virtual webSites Available}

The EPS EurophysNet WWW service is testing a prototype Virtual webSite (VS) service at http://epswww.epfl.ch / kps which can be up-loaded by email. Physical societies having difficulty accessing Internet but able to send email messages are being offered webSites. Please contact the Editor for information.

\section{Hewlett-Packard Europhysics Prize}

The Selection Committee for the HewlettPackard Europhysics Prize invites nominations for the 1997 award. The Prize is given for an outstanding contribution to condensed matter physics within the last five years, with the potential for leading advances in electronic, electrical or materials engineering.

Nominations may be submitted by EPS members (Individual Ordinary Members and National Society Members) as individuals or as a representative of a Division, Section or Group. Previous winners have been D.R. Huffman, W. Krätschmer, H.W. Kroto, and R.E. Smalley (1994) and R.H. Friend (1995). To maintain the extremely high standard, it is necessary that the
Committee receives proposals which represent the breadth and strength of European condensed matter physics. Proposals should include the motivation for the award and include, if possible, a brief curriculum vitae of the each of the nominees and a short list of major publications. Letters of support from authorities in the field which outline the importance of the work are also very helpful. Proposals will be treated in confidence, and although they are acknowledged, there will be no correspondence. Nominations should be sent before 15 December 1996 to the Selection Committee, Hewlett-Packard Euro-physics Prize, EPS, PB 69, CH-1213 Petit-Lancy 2. 